\title{
Derivation of Regression Equation for Estimation of Height from the Length of Clavicles
}

\author{
BipinchandraA. Khade ${ }^{1}$, Dr. Vaibhav P. Anjankar², \\ A.S. Mangalgiri ${ }^{3}$, Anil J. Anjankar ${ }^{4}$, Vilas K. Chimurkar ${ }^{5}$ \\ ${ }^{1}$ Associate Professor of Anatomy, Chirayu Medical College and Hospital, Bhopal, ${ }^{2}$ Associate Professor of \\ Anatomy, Jawaharlal Nehru Medical College, Datta Meghe Institute of Medical Sciences, Sawangi (Meghe), \\ Wardha, ${ }^{3}$ Professor of Anatomy, Chirayu Medical College and Hospital, Bhopal, ${ }^{4}$ Professor and Head, Department \\ of Forensic medicine and Toxicology, Jawaharlal Nehru Medical College, Datta Meghe Institute of Medical \\ Sciences, Sawangi (Meghe), Wardha, ${ }^{5}$ Professor and Head, Department of Anatomy, Jawaharlal Nehru Medical \\ College, Datta Meghe Institute of Medical Sciences, Sawangi (Meghe), Wardha
}

\begin{abstract}
Background: The various features of clavicle help to decide the gender and height of the individual. Stature is an important biological parameter in medico-legal forensic examination. The length of clavicle is considered as an important anthropological parameter. The present study was undertaken with the aim of deriving of regression equation for estimation of height from the lengths of clavicle.

Methodology: This cross sectional, observational study was conducted from October 2019 to February 2020 after getting approval from IEC. 489 healthy subjects (290 males and 199 females) were included in the study after getting the informed consent. Length of clavicle and height of individual were measured and mean was calculated. Regression equations were derived after statistical analysis.

Results: The values obtained by statistical analysis were found statistically significant. Equation were derived for estimation of height from right and left clavicles in males as well as females. The mean lengths of right sided clavicles are more than that of left sided clavicles in both the genders.

Discussion: Stature estimation is key parameter in the identification process of unknown individuals in which human remains are found in mutilated form or as skeletal remains. In the present study, we attempted to correlate the lengths of clavicle with stature of individual. The present study also proved that lengths of clavicles are more in males than in females which can be attributed to heavy built in males.
\end{abstract}

Keywords: Stature; correlation; mutilated; anthropological; decomposing.

\section{Introduction}

The clavicle is a modified long bone. It is the only long bone that lies horizontally, and shows variations in its morphometry. The locomotor behavior of superior

\section{Corresponding Author:}

\section{Dr. Vaibhav P. Anjankar}

Associate Professor of Anatomy, Jawaharlal Nehru Medical College, Datta Meghe Institute of Medical Sciences, Sawangi (Meghe), Wardha 442004, Maharashtra, India Mobile No.: 09422856368, 09589733460 e-mail: vaibhav_anjankar@yahoo.co.in extremity relies mostly on clavicle morphometry. The various features of clavicle help to decide the gender and height of the individual.

The length of clavicle is considered as an important anthropological parameter which is described as the distance between the lateral-most point of the clavicle in the acromio-clavicular joint and the medial-most point of the clavicle in the sterno-clavicular joint ${ }^{1}$. Black $\mathrm{S}$ and Scheuer $\mathrm{L}^{1}$ have mentioned that most of the adult morphological features of clavicle in humans are developed very early in fetal life well before birth ${ }^{3}$. Clavicle attains $80 \%$ of its total length by 12 years in males and 9 years in females ${ }^{4}$. 
Stature is an important biological parameter in medico-legal forensic examination ${ }^{5}$. The linear measurement of individual body parts plays very important role in the field of forensic, anatomical and anthropological sciences ${ }^{6}$. Out of various criteria for personal identification, stature carries the significant value. Anthropological database can be prepared from four basic parameters- age, race, stature and gender.

Establishment of an identity is very much important in both civil and criminal cases. Sometimes mutilated or decomposed bodies or the fragmentary remains of skeleton are brought for medico-legal examination ${ }^{5}$. This is common in Indian set up where victims are attacked by wild animals in forests. This leads to difficulty in identification of the deceased ${ }^{5}$. Literature shows many studies on stature estimation from percutaneous body measurements. But stature estimation from clavicle length is very rarely done especially in central India region. So, we have attempted to estimate the stature of individual from the clavicle length.

\section{Material and Method}

The present cross sectional, observational study was conducted in the department of Anatomy from October 2019 to February 2020 over a period of five months. The protocol was approved by the Institutional Ethics Committee. All the participants were informed about the procedure of the study and informed consent was taken before taking the measurements.

Total of 489 apparently healthy subjects of both the sexes were involved in the study. The age group of the participants was 18 to 30 years. Lower age limit of 18 years was considered because stature at this age is considered as adult height ${ }^{7}$ and multiplication factor remains mostly constant ${ }^{8}$. Apparently healthy subjects without any noticeable deformities (congenital or acquired) of the spine or upper extremities were included in the study.

The length of clavicle was measured with the vernier caliper using palpable landmarks- most medial most point of the clavicle on the sterno-clavicular joint and the lateral most point of the clavicle on the acromioclavicular joint.

Height of the individual was measured using stadiometer in standing positionwhere he/she was asked to stand barefoot.
All the measurements were taken thrice and mean of it was used for documentation.

Statistical Analysis: All the values were analyzed statistically using SPSS software Version 22. Mean and standard deviations were calculated for both genders. Linear regression and correlation coefficients were calculated separately for males and females. Equations were derived in both genders individually for right and left sided clavicles.

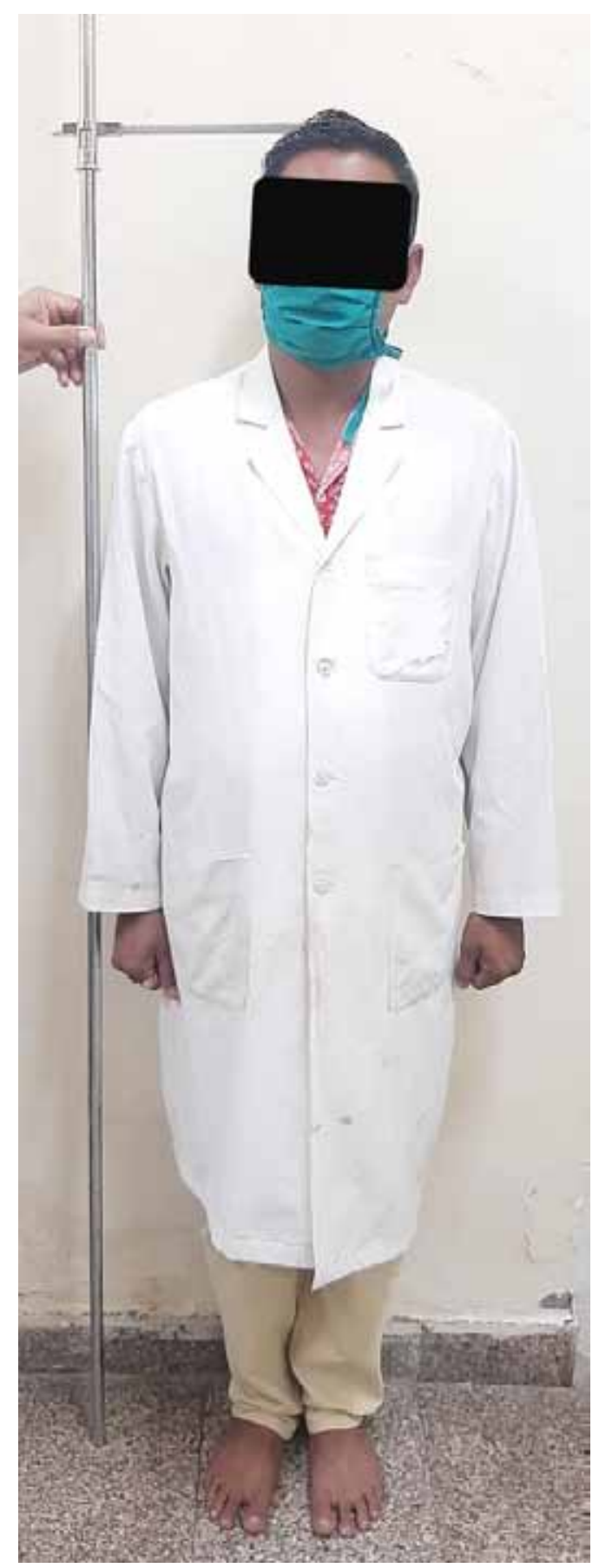

Figure 1: Measurements of height 


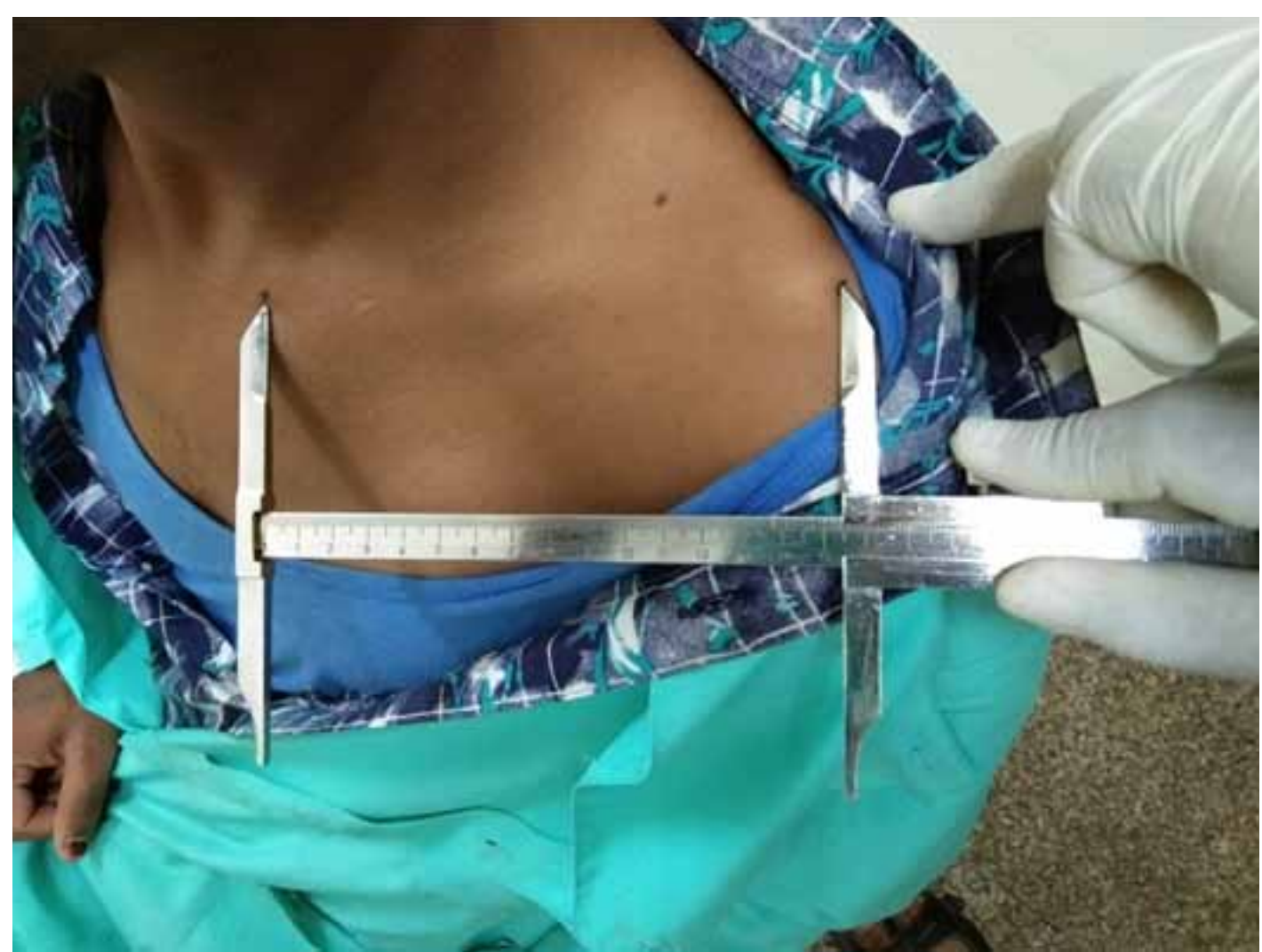

Figure 2 Measurement of length of clavicle

\section{Results}

Out of 489 participants, 290 were male and 199 were females. Demographic distribution of the involved subjects in mentioned in table I for males and table II for females.

Table I: Demographic parameters in males

\begin{tabular}{|l|c|c|c|c|}
\hline & Minimum & Maximum & Mean & Std. Deviation \\
\hline Age (Years) & 18.00 & 30.00 & 26.7800 & 1.10627 \\
\hline MH & 158.40 & 182.80 & 172.6780 & 5.79212 \\
\hline MRTC & 13.80 & 17.50 & 15.8470 & 0.93002 \\
\hline MLTC & 14.00 & 17.60 & 15.6970 & 0.89932 \\
\hline
\end{tabular}

$\mathrm{MH}=$ Height in male $(\mathrm{cm}) \mathrm{MRTC}=$ length of right clavicle in male $(\mathrm{cm}) \mathrm{MLTC}=$ length of left clavicle in male $(\mathrm{cm})$

Table II: Demographic parameters in females

\begin{tabular}{|l|c|c|c|c|}
\hline & Minimum & Maximum & Mean & Std. Deviation \\
\hline Age (Years) & 18.00 & 28.00 & 25.6900 & 0.07205 \\
\hline FH & 151.00 & 179.60 & 161.3170 & 0.53973 \\
\hline FRTC & 12.80 & 16.10 & 14.1710 & 0.10049 \\
\hline FLTC & 12.60 & 16.10 & 14.0420 & 0.09911 \\
\hline
\end{tabular}

$\mathrm{FH}=$ Height in female $(\mathrm{cm}) \mathrm{FRTC}=$ length of right clavicle in female $(\mathrm{cm}) \mathrm{FLTC}=$ length of left clavicle in female $(\mathrm{cm})$ 
Table III: Correlations for height in males (MH) with length of right clavicle in males (MRTC) and length of left clavicle in males (MLTC)

\begin{tabular}{|c|c|c|c|c|c|c|c|}
\hline \multicolumn{4}{|c|}{ Correlations of MH with MRTC } & \multicolumn{4}{|c|}{ Correlations of MH with MLTC } \\
\hline & & MH & MRTC & & & MH & MLTC \\
\hline \multirow{3}{*}{$\mathrm{MH}$} & Pearson Correlation & 1 & $0.829 * *$ & \multirow{3}{*}{$\mathrm{MH}$} & Pearson Correlation & 1 & $0.823 * *$ \\
\hline & Sig. (2-tailed) & & 0.000 & & Sig. (2-tailed) & & 0.000 \\
\hline & $\mathrm{N}$ & 100 & 100 & & $\mathrm{~N}$ & 100 & 100 \\
\hline \multirow{3}{*}{ MRTC } & Pearson Correlation & $0.829 * *$ & 1 & \multirow{3}{*}{ MLTC } & Pearson Correlation & $0.823 * *$ & 1 \\
\hline & Sig. (2-tailed) & 0.000 & & & Sig. (2-tailed) & 0.000 & \\
\hline & $\mathrm{N}$ & 100 & 100 & & $\mathrm{~N}$ & 100 & 100 \\
\hline
\end{tabular}

**. Correlation is significant at the 0.01 level (2-tailed).

Equation for height and right clavicle in males (MRTC): Height $=5.160 \times \mathrm{MRTC}+90.908$

Equation for height and left clavicle in males (MLTC): Height $=5.302 \mathrm{x}$ MLTC +89.453

Table IV: Correlations for height in females (FH) with length of right clavicle in females (FRTC) and length of left clavicle in females (FLTC)

\begin{tabular}{|c|c|c|c|c|c|c|c|}
\hline \multicolumn{4}{|c|}{ Correlations of FH with FRTC } & \multicolumn{4}{|c|}{ Correlations of FH with FLTC } \\
\hline & & FH & FRTC & & & FH & FLTC \\
\hline \multirow{3}{*}{ FH } & Pearson Correlation & 1 & $0.830 * *$ & \multirow{3}{*}{ FH } & Pearson Correlation & 1 & $0.835 * *$ \\
\hline & Sig. (2-tailed) & & 0.000 & & Sig. (2-tailed) & & 0.000 \\
\hline & $\mathrm{N}$ & 100 & 100 & & $\mathrm{~N}$ & 100 & 100 \\
\hline \multirow{3}{*}{ FRTC } & Pearson Correlation & $0.830 * *$ & 1 & \multirow{3}{*}{ FLTC } & Pearson Correlation & $0.835 * *$ & 1 \\
\hline & Sig. (2-tailed) & 0.000 & & & Sig. (2-tailed) & 0.000 & \\
\hline & $\mathrm{N}$ & 100 & 100 & & $\mathrm{~N}$ & 100 & 100 \\
\hline
\end{tabular}

Equation for height and right clavicle in females (FRTC): Height $=4.456$ x FRTC +98.178

Equation for height and left clavicle in females (FLTC): Height $=4.549 \times$ FLTC +97.445

\section{Discussion}

Stature estimation is key parameter in the identification process of unknown individuals in which human remains are found in mutilated form or as skeletal remains. Stature calculation from decomposing and incomplete skeletal remains is gold standard in establishing the identity of individual in anthropological studies and forensic examinations ${ }^{6,7}$. Literature shows various studies undertaken on the stature determination from dry clavicle bones but very few studies are available where height is determined from the clavicle when the soft tissues are intact around it. It is easier to measure the length of dry clavicle as compared when it's covered with soft tissues i.e. percutaneous measurements. In the present study, we attempted to correlate the lengths of clavicle with stature of individual.
The major conclusion in the present study is that the mean lengths of right sided clavicles are more than that of left sided clavicles in both the genders. Sehrawat JS and Pathak $\mathrm{RK}^{3}$ (2016) also observed bilateral asymmetry in all parameters like length, weight, midclavicular circumference etc. They further advocated that right clavicle is more robust due to its greater sagittal diameter and higher development of most of the ligaments and muscles than the left clavicles ${ }^{3}$. Another differentiating factor might be physical activity pattern of right and side. King PR et $\mathrm{al}^{8}$ (2014) found longer left clavicle than the right clavicle in $65 \%$ male $(4.55$ $\mathrm{mm})$ and $67 \%$ female $(3.14 \mathrm{~mm})$ cases. Cunningham et $\mathrm{al}^{9}$ (2013), found $28 \%$ clavicles were length-wise asymmetric (with up to $5 \mathrm{~mm}$ side differences) ${ }^{3}$. The different effects of genetic changes, mechanical loadings 
and the muscular attachments might be responsible for such asymmetries of the clavicle $3,10,11,12$. The various factors that may affect the lengths of clavicles are genetic, nutrition, geographical location, physical activity, and different races ${ }^{6,13}$. The study carried out by Yashoda et $\mathrm{al}^{14}$ (2011) in New Delhi population postulated that mean length of the left clavicle was higher than the mean length of the right clavicle for both sexes. Similar results were observed by Ukoha UU et $\mathrm{al}^{1}$ (2019) in North Eastern Nigerian population.

The present study also proved that lengths of clavicles are more in males than in females which can be attributed to heavy built in males. Other possible factors might be higher skeletal size and body mass ${ }^{1,13}$. The study conducted by Pande V et all ${ }^{14}$ (2020) for correlation between stature and length of clavicle in female population in central India concluded with positive correlation and the linear relationship between the living stature and length of clavicle of either side. But the sample size was just 50 .

\section{Conclusion}

We derived regression equations for height calculation from length of right and left clavicles in both males and females. These regression equations will be very helpful for calculating height of an individual from the length of clavicle.

Funding: This research received no specific grant from any funding agency in the public, commercial, or not-for-profit sectors.

Conflicts of Interest: The Authors declares that there is no conflict of interest

\section{Reference}

1. Ukoha UU, Okeke CM, Ukoha C, Ekezie J, Onyenankeya KR. Estimation of Stature Using the Clavicular Length of Adults in South-Eastern Nigerian. National Journal of Medical Research. Oct-Dec, 2019; 9(4): 141-4.

2. Black S and Scheuer L. Age changes in the clavicle from early neonatal period to skeletal maturity. Int. J. Osteoarchaeo. 1996; 6; 425-34

3. Sehrawat JS and Pathak RK. Variability in anatomical features of human clavicle: Its forensic anthropological and clinical significance. Translational Research in Anatomy. 2016; 3 (4): 5-14.
4. McGraw MA, Mehlman CT, Lindsell CJ, Kirby CL, Postnatal growth of the clavicle: birth to 18 years of age, J. Pediatr. Orthop. 2009; 29: 937-43.

5. Wankhede KP et al. Estimation of Stature from Head Length \& Head breadth in Central Indian Population: An Anthropometric Study. Int J Anat Res 2015, 3(1):954-57.

6. Shahzan MS, Babu KY, Mohanraj KG. Estimation of stature using clavicle bone.Drug Invention Today. 2018; 10(2): 3066-8.

7. Mansur D, Haque M, Sharma K, Karki R, Khanal K, Karna R. Estimation of stature from foot length in adult Nepalese population and its clinical relevance. Kathmandu Univ Med J 2012;10:11-5.

8. King PR, Scheepers S, Ikram A, Anatomy of clavicle and its intermedullary canal: a computed tomography study, Eur. J. Orthop. Surg. Traumat 24 (2014), 37e42.

9. Cunningham BP, McLaren A, Richardson M, McLemore R. Clavicular length: the assumption of symmetry, Orthopedics 36 (2013) e343ee347.

10. M.A. Harrington, T.S. Keller, J.G. Seiler, D.R. Weikert, E. Moeljanto, H.S. Schwartz, Geometric properties and the predicted mechanical behavior of adult human clavicles, J. Biomech. 26 (1993) $417 \mathrm{e} 426$.

11. J. Steele, S. Mays, Handedness and directional asymmetry in the long bones of the human upper limb, Int. J. Osteoarchaeol. 5 (1995) 39e49.

12. R. Sellards, Anatomy and biomechanics of acromio-clavicular joint, Oper.techn Sport Med. 12 (2004) 2e5.

13. Akhlaghi M, Hajibeygi M, Zamani N, Moradi B. Estimation of stature from upper limb anthropometry in Iranian population. Journal of Forensic and Legal Medicine. 2012;19:280-4

14. Yashoda R, Shrabranak KN, Avnish KS, Atul M. Correlation of Stature of Adult with the Length of the clavicle of New Delhi population. J Indian Acad Forensic Med. 2011; 33: 3.

15. Pande V, Patond and Patil B. Correlation between Stature and Length of Clavicle in Female Population of Central India. Indian Journal of Forensic Medicine \& Toxicology, July-September 2020, 14(3), 511-4. 